\title{
Estudo de caso: aplicabilidade em dissertações na área de ciência da informação
}

\author{
Paulo Marcelo Carvalho Holanda \\ Universidade Federal de Minas Gerais, Escola de Ciência da Informação, Belo Horizonte, MG, Brasil \\ pholanda515@gmail.com \\ Júlia Rocha Ribeiro \\ Universidade Federal de Minas Gerais, Escola de Ciência da Informação, Belo Horizonte, MG, Brasil \\ julia34rr@gmail.com \\ Miriam Cândida de Jesus \\ Universidade Federal de Minas Gerais, Escola de Ciência da Informação, Belo Horizonte, MG, Brasil \\ miriamcandidadejesus@gmail.com
}

DOI: https://doi.org/10.26512/rici.v13.n2.2020.25012

Recebido/Recibido/Received: 2019-06-04

Aceitado/Aceptado/Accepted: 2020-05-06

Resumo: Apresenta uma análise sobre a aplicação da metodologia de estudo de caso em dissertações da Biblioteca Digital Brasileira de Teses e Dissertações, com o objetivo de descobrir como estão sendo utilizados os "Estudos de caso" nas metodologias das dissertações no campo da "Ciência da Informação". Foi utilizada a busca de dissertações, do ano de 2017, da Ciência da Informação, para identificar quais utilizaram o estudo de caso em sua metodologia e como foram utilizados esses estudos de caso. O recorte "Dissertações" foi necessário devido ao tempo limitado em vista do extenso universo de trabalhos que utilizam a metodologia de "Estudo de caso". Dentre os 26 trabalhos retornados, após a leitura dos resumos, foram constatados que 23 eram direcionados para a metodologia do estudo de caso, e que, também eram direcionados a alguma área de pesquisa da Ciência da informação. Em seguida foi feita a leitura dos trabalhos selecionados e análise de acordo com os parâmetros de Yin.

Palavras-Chave: estudo de caso. Ciência da Informação. metodologia científica.

Estudio de caso: aplicabilidad en disertaciones en el área de ciencias de la información

Resumen: En el presente trabajo se analizan los resultados obtenidos en el análisis de la metodología de estudio de casos en las disertaciones de la Biblioteca Digital Brasileña de Tesis y Disertaciones, con el objetivo de descubrir cómo se están utilizando los "Estudios de caso" en las metodologías de las disertaciones en el campo de la "Ciencia de la Información". Se utilizó la búsqueda de disertaciones, del año 2017, de la Ciencia de la Información, para identificar cuáles utilizaron el estudio de caso en su metodología y cómo se utilizaron esos estudios de caso. El recorte "Disertaciones" fue necesario debido al tiempo limitado en vista del extenso universo de trabajos que utilizan la metodología de "Estudio de caso". De los 26 trabajos retornados, después de la lectura de los resúmenes, fueron constatados que 23 eran dirigidos a la metodología del estudio de caso, y que, también se dirigían a alguna área de investigación de la Ciencia de la información. En seguida se hizo la lectura de los trabajos seleccionados y análisis de acuerdo con los parámetros de Yin.

Palabras clave: estudio de caso. Ciencia de la Información. metodología científica.

Case study: applicability in dissertations in the area of Information Science

Abstract: Presents an analysis about the application of the case study methodology in dissertations of the Brazilian Digital Library of Theses and Dissertations, with the objective of discovering how the "Case Studies" are being used in the methodologies of the dissertations in the field of "Information". We used the search for dissertations, from the year 2017, on Information Science, to identify which ones used the 
case study in its methodology and how these case studies were used. The "Dissertations" clipping was necessary due to the limited time in view of the extensive universe of works that use the "Case Study" methodology. Among the 26 papers returned, after reading the abstracts, it was verified that 23 were directed to the methodology of the case study, and that they were also directed to some area of information science research. Then the selected papers were read and analyzed according to the Yin parameters.

Keywords: case study. Information Science. scientific methodology.

\section{Introdução}

Propõe-se nesse artigo investigar a metodologia de pesquisa "Estudo de Caso", com ênfase na sua utilização no contexto da Ciência da Informação. Com essa questão pretende-se analisar como ela está sendo utilizada nessa área.

A partir de uma proposta de discutir esse assunto, foi definido que primeiramente é necessário fazer uma revisão teórica, a fim de esclarecer o método "Estudo de Caso", suas características, tipologias, procedimentos, maneiras de conduzí-lo, coleta e análise de dados, etc... Em um segundo momento foram definidos a partir dessa revisão os parâmetros para análise. Fazer um recorte em relação ao tipo de material, tempo e base de dados a ser utilizada, foi imprescindível, para realizar as análises. O objetivo do artigo dessa forma é descobrir de que maneira essa utilização do método "Estudo de Caso" foi realizada em dissertações na área da Ciência da Informação, no ano de 2017.

O estudo de caso é utilizado há muito tempo em diferentes áreas do conhecimento tais como sociologia, antropologia, serviço social, direito e administração. A origem dos estudos de caso na sociologia e na antropologia remonta ao final do século XIX e início do século XX, com Fréderic Le Play, na França, e Bronislaw Malinowski e membros da Escola de Chicago, nos Estados Unidos, tendo como principal propósito desses estudos realçar as características da vida social.

Na medicina, na psicanálise e no serviço social objetivaram estudar um estudo de caso geralmente problemático, para fins de diagnose, tratamento ou acompanhamento. Em direito, administração e medicina foram e ainda são usados como recurso didático, seja pela facilidade de ilustrar o uso de um procedimento, seja para estimular, em situação de ensino, o debate do tema.

Na educação os estudos de casos apareceram em manuais de metodologia de pesquisa nas décadas de 1960 e 1970, voltados para um sentido restrito de estudos descritivos de uma unidade.

O caso pode ser algo bem definido ou concreto, como um indivíduo, um grupo ou uma organização, mas também pode ser algo menos definido ou definido num plano mais abstrato como, decisões, programas, processos de implementação ou mudanças organizacionais. 
A análise dos dados se dará ao categorizar e classificar os trabalhos selecionados em gráficos e/ou tabelas, o que permitirá a visualização das características destes trabalhos quanto às categorias propostas por Yin.

\section{Conceitos e definições}

Yin (2015) define caso como determinado fenômeno contemporâneo dentro de seu contexto de vida real, especialmente quando os limites entre o fenômeno e o contexto não são claros e o pesquisador tem pouco controle sobre o fenômeno e o contexto.

Stake (1995) concorda com a opinião de Louis Smith (1978): os pesquisadores devem ver um caso como um sistema limitado e investigá-lo "como um objeto ao invés de um processo".

Merriam (1998), vê o caso como uma coisa, uma única entidade, uma unidade em torno da qual existem limites, o caso pode ser uma pessoa, um programa, um grupo, uma política específica e assim por diante.

Um estudo de caso é uma investigação empírica que investiga um fenômeno contemporâneo dentro do seu contexto de vida real, especialmente quando os limites entre o fenômeno e o contexto não estão claramente definidos (YIN, 2015).

Segundo Stake (1995), estudo de caso é um "estudo da particularidade e complexidade de um único caso, chegando a compreender a sua atividade dentro de circunstâncias importantes".

Para Merriam (1998), o estudo de caso é uma descrição intensa, holística, bem como uma análise de um fenômeno limitado, como um programa, uma instituição, uma pessoa, um processo ou uma unidade social.

Segundo GIL (2007), é um estudo de uma entidade bem definida como um programa, uma instituição, um sistema educativo, uma pessoa, ou uma unidade social, visando conhecer em profundidade o "como" e o "porquê" de uma determinada situação que se supõe ser única em muitos aspectos.

Geralmente são indicados como estratégia como se colocam questões "como" e "por que"; se o pesquisador tem pouco controle sobre os eventos; e se o foco se encontra em fenômenos contemporâneos inseridos em algum contexto da vida real, de acordo com Yin (2015):

- O fenômeno é observado em seu ambiente natural.

- Um ou mais entes (pessoas, organizações) são examinados.

- A complexidade do caso é estudada intensamente. 
- Não são utilizados controles experimentais.

- Requer um problema que pede a compreensão holística de um evento ou de uma situação usando a lógica indutiva, do particular ou específico para o geral. A natureza da investigação poderá ser Qualitativa ou Quantitativa, segundo Stake (1995).

As que possuem 'Carácter holístico', segundo Yin (2015), visam uma maior concentração no todo, para chegar a compreender o fenômeno na globalidade e não alguma particularidade ou diferenciação de outros casos (Stake, 1995).

Quanto à importância do contexto, Yin (2015) parece atribuir mais importância a ele, em alguns tipos de estudos de caso, como os estudos descritivos, quando os define como: um estudo de caso descritivo apresenta uma descrição exaustiva de um fenômeno, dentro do respectivo contexto.

No tocante à capacidade de poder fazer generalizações, Stake (1995) distingue entre "pequenas generalizações" e "grandes generalizações".

Yin (2015) lembra que a metodologia pressupõe, em alguns casos, a existência de uma teoria prévia, que será testada no decorrer da investigação e admite em outros casos a construção de uma teoria a partir dos achados da pesquisa.

O 'Carácter interpretativo', conforme Stake (1995), fala de questões temáticas como necessárias para a orientação na estruturação das observações, das entrevistas e da revisão de documentos. À medida que se avança na compreensão do caso, através de novas observações e confirmação das antigas, o investigador vai reformulando as questões temáticas iniciais.

Stake (1995) propõe uma também uma classificação bem explicativa, com base nos objetivos que os investigadores possuem ao empreender a metodologia de estudo de caso:

- estudos de caso intrínsecos: o interesse da investigação, recai sobre o caso particular;

- estudos de casos instrumentais: definem em função do interesse por conhecer e compreender uma problemática mais ampla, através da compreensão do caso particular;

- estudos de caso coletivos: os investigadores estudam vários casos a fim de fazer uma melhor análise e, consequentemente, uma melhor compreensão e teorização.

Ao conduzir estudos de caso, serão necessárias determinadas habilidades do pesquisador, tais como, segundo Yin (2015):

$>$ Capacidade de fazer boas perguntas;

$>$ Saber "ouvir"; 


\footnotetext{
$>\quad$ Adaptabilidade e flexibilidade;

$>$ Ter uma noção clara das questões que estão sendo estudadas;

Ausência de viés (imparcialidade).
}

\section{0 uso do método de estudo de caso}

A elaboração do projeto de pesquisa tem uma influência direta sobre os resultados a serem obtidos e a validade das conclusões tiradas do trabalho e ele serve de guia para todo o trabalho do investigador. Para se utilizar do método Estudo de Caso é necessário definir qual será a unidade de análise. Ela pode ser um indivíduo, uma decisão, um programa, pode ser sobre a implantação de um processo, sobre uma mudança organizacional, entre outras. A definição da unidade de análise está ligada à maneira pela qual as questões de estudo foram definidas.

Abordaremos o uso do método estudo de caso e sua condução utilizando princípios e conceitos discutidos por Yin (2015), pois dessa forma conseguiremos analisar posteriormente as dissertações de uma maneira mais clara, definindo assim a partir dessas características os parâmetros para sistematizar os resultados.

Um dos primeiros passos mais importante na utilização do da metodologia de estudo de caso em pesquisas é a definição da sua abordagem (qualitativa, quantitativa ou a combinação de ambas). Yin (2005), fala sobre a relevância de utilizar, em alguns métodos de investigação, simultaneamente dados qualitativos e quantitativos. A utilização de dados qualitativos e quantitativos, na mesma investigação, vai no sentido de olhar para estas metodologias como complementares e não como opostas ou rivais.

Yin (2015) separa os estudos de caso em único ou múltiplos com dois enfoques de análise, o holístico e o incorporado. Casos únicos, segundo ele, são válidos e decisivos para testar a teoria, quando é raro ou extremo; quando é representativo ou típico, ou seja, se assemelha a muitos outros casos; quando é revelador, ou seja, quando o fenômeno é inacessível; e longitudinal, em que se estuda o caso único em momentos distintos no tempo; Já os casos múltiplos são mais consistentes e permitem maiores generalizações, mas demandam maiores recursos e tempo por parte do pesquisador; ambos podem ter o enfoque incorporado que envolve mais de uma unidade de análise no estudo de caso ou o enfoque holístico que examina a natureza global, como um todo.

Outro ponto importante, citado, por Yin (2015) é o propósito do Estudo de caso, que pode ser: 
- Explanatório: procuram informação que possibilite o estabelecimento de relações de causa-efeito, ou seja, procuram a causa que melhor explica o fenômeno estudado e todas as suas relações causais.

- Exploratório: O objetivo é prover o pesquisador de maior conhecimento sobre o tema ou problema de pesquisa. Contribui para esclarecer uma situação na qual as informações são escassas. Têm como finalidade definir as questões ou hipóteses para uma investigação posterior. Isto é, são o prelúdio para uma investigação subsequente, mas não necessariamente um estudo de caso.

- Descritivo: Representam a descrição completa de um fenômeno inserido no seu contexto. Ajuda à compreensão de acontecimentos. Possuem objetivos bem definidos, com procedimentos formais estruturados e dirigidos para a solução de problemas ou avaliação de alternativas de cursos de ação.

O autor sugere que para uma melhor eficácia do estudo de caso seja elaborado um protocolo para sua condução. O protocolo contém os procedimentos e as regras gerais que deveriam ser seguidas ao se utilizar o estudo de caso. O protocolo é desejável para o estudo de caso em qualquer circunstância, mas é essencial quando se utilizar um projeto de casos múltiplos, devendo apresentar as seguintes seções:

- Uma visão geral do projeto do estudo de caso

Procedimentos de campo (acesso, materiais, etc...)

Questões do estudo de caso

Guia para o relatório do estudo de caso

São um conjunto de questões substantivas que refletem a investigação real. Os estudos de caso apresentam os seguintes tipos de estruturas ilustrativas para a sua composição, trazidos por Yin (2015):

> Analítica linear: esta abordagem padrão para composição de relatórios de pesquisa. A sequência de subtópicos inicia com o aspecto ou problema sendo estudo e com uma revisão da literatura, e os subtópicos prosseguem, então, para cobrir os métodos usados, os dados coletados, a análise de dados, as descobertas e terminando com as conclusões e suas implicações para a questão ou problema inicial estudo;

- Comparativa: repete o mesmo material de estudo de caso duas ou mais vezes, comparando as descrições ou explicações alternativas do mesmo caso; 
> Cronológica: a sequência dos capítulos ou das seções pode seguir as fases iniciais, intermediárias e finais de um caso, ou seja, as sequências causais presumidas devem ocorrer linearmente ao longo do tempo. Se a causa presumida de um evento ocorrer após o evento ter ocorrido, haverá razão para questionar a proposição causal inicial..

- De construção de teoria: a sequência dos capítulos ou as seções seguirá alguma lógica de construção teórica. A lógica dependerá do tópico e da teoria específica, mas cada capítulo ou seção deve revelar uma parte do nova do argumento teórico feito.

- De "suspense": inverte a abordagem analitica descrita previamente. O principal resultado do estudo de caso e sua significação substantiva são, paradoxalmente, apresentados no capítulo ou na seção inicial, sendo que o restante do estudo de caso dedica-se ao desenvolvimento de uma explicação do resultado.

- Não-sequencial: é aquela na qual a sequência de seções ou dos capítulos não assume importância especial, muitas vezes, para estudos de caso descritivos, onde poderia mudar a ordem das seções ou capítulos sem alterar o seu valor descritivo.

\subsection{Da condução do estudo de caso}

O Método do Estudo de Caso obtém evidências a partir de seis fontes de dados: documentos, registros de arquivos, entrevistas, observação direta, observação participante e artefatos físicos e cada uma delas requer habilidades específicas e procedimentos metodológicos específicos.

Documentação: Este tipo de informação pode assumir muitas formas e deve ser o objeto de planos explícitos da coleta de dados. A documentação, pela sua própria característica, é uma importante fonte de dados e nela as informações podem tomar diversas formas como cartas, memorandos, agendas, atas de reuniões, documentos administrativos, estudos formais, avaliações de plantas e artigos da mídia.

Registros em arquivos: Estes dados podem ser (YIN, 2015) dados de serviços, como número de clientes, dados organizacionais - orçamentos, mapas e quadros - para dados geográficos, lista de nomes, dados de levantamentos, dados pessoais - como salários, listas de telefone, que podem ser usados em conjunto com outras fontes de informações tanto para verificar a exatidão como para avaliar dados de outras fontes. Os dados arquivados, em um computador, podem ser relevantes para muitos estudos de caso.

Entrevistas: Esta é uma das fontes de dados mais importantes para os estudos de caso, apesar de haver uma associação usual entre a entrevista e metodologia de 'survey' (YIN, 2015). 
A entrevista, dentro da metodologia do Estudo de Caso, pode assumir várias formas, como a estruturada, semi-estruturada ou espontânea.

Observação direta: Ao realizar uma visita de campo ao "local" escolhido para o estudo de caso, você está criando a oportunidade de fazer observações diretas. Podem variar de atividades formais a atividades informais de coleta de dados. Pode-se desenvolver protocolos de observação.

Observação participante: 0 pesquisador participa dos eventos que estão sendo estudados. Nesse caso ele não é apenas um observador passivo. Esta participação pode ser através de interações sociais informais, atividades específicas, o pesquisador pode ter um papel funcional, ou ser membro da equipe da organização ou até mesmo ser a pessoa que toma as decisões chave, etc.

Artefatos físicos: Pode ser um aparelho de alta tecnologia, uma ferramenta ou instrumento tecnológico, uma obra de arte, ou alguma outra evidência física. Esses artefatos podem ser coletados ou observados.

Quadro 1 - Seis fontes de evidência: pontos fortes e pontos fracos

\begin{tabular}{|c|c|c|}
\hline $\begin{array}{l}\text { Fonte } \\
\text { de } \\
\text { evidên- } \\
\text { cias }\end{array}$ & Pontos fortes & Pontos fracos \\
\hline $\begin{array}{l}\text { Docume } \\
\text { ntação }\end{array}$ & $\begin{array}{l}\text {-estável(pode ser revisada inúmeras vezes) } \\
\text {-discreta (não foi criada como resultado do } \\
\text { estudo de caso) } \\
\text {-exata (contém nomes, referências e } \\
\text { detalhes exatos de um evento) } \\
\text {-ampla cobertura (longo espaço de tempo, } \\
\text { muitos eventos e muitos ambientes } \\
\text { distintos) }\end{array}$ & $\begin{array}{l}\text {-capacidade de recuperação (Pode ser } \\
\text { baixa) } \\
\text {-seletividade tendenciosa, se a coleta } \\
\text { não estiver completa } \\
\text {-relato de vieses (reflete as idéias } \\
\text { preconcebidas, desconhecidas) do } \\
\text { autor } \\
\text {-acesso (pode ser negado) }\end{array}$ \\
\hline $\begin{array}{l}\text { Regis- } \\
\text { tros em } \\
\text { arqui- } \\
\text { vos }\end{array}$ & $\begin{array}{l}\text {-[os mesmos mencionados para } \\
\text { documentação] } \\
\text {-precisos e quantitativos }\end{array}$ & $\begin{array}{l}\text {-[os mesmos mencionados para } \\
\text { documentação] } \\
\text {-acessibilidade aos locais devido a } \\
\text { razões particulares }\end{array}$ \\
\hline $\begin{array}{l}\text { Entre- } \\
\text { vistas }\end{array}$ & $\begin{array}{l}\text {-direcionadas (enfocam diretamente o tópico } \\
\text { do estudo de caso) } \\
\text {-perceptivas (fornecem inferências causais } \\
\text { percebidas) }\end{array}$ & $\begin{array}{l}\text {-vieses devido a questões mal } \\
\text { elaboradas } \\
\text {-respostas viesadas } \\
\text {-ocorrem imprecisões (devido ao } \\
\text { entrevistado) } \\
\text {-reflexibilidade (dá resposta que o } \\
\text { entrevistador quer ouvir) }\end{array}$ \\
\hline
\end{tabular}




\begin{tabular}{|l|l|l|}
\hline $\begin{array}{l}\text { Observa } \\
\text { ções } \\
\text { diretas }\end{array}$ & $\begin{array}{l}\text {-realidade (tratam de acontecimentos em } \\
\text { tempo real) }\end{array}$ & $\begin{array}{l}\text {-consomem muito tempo } \\
\text {-contextuais (tratam do contexto do evento) } \\
\text {-reflexibilidade(evento pode ocorrer de } \\
\text { forma diferenciada porque está sendo } \\
\text { observado) } \\
\text {-custo (horas necessárias pelos } \\
\text { observadores humanos) }\end{array}$ \\
\hline $\begin{array}{l}\text { Observa } \\
\text { ção } \\
\text { particip } \\
\text { ante }\end{array}$ & $\begin{array}{l}\text {-[os mesmos mencionados para observação } \\
\text { direta] } \\
\text { razões interpessoais }\end{array}$ & $\begin{array}{l}\text {-[os mesmos mencionados } \\
\text { observação direta] } \\
\text {-vieses devido à manipulação dos } \\
\text { eventos por parte do pesquisador }\end{array}$ \\
\hline $\begin{array}{l}\text { Arte- } \\
\text { fatos } \\
\text { físicos }\end{array}$ & $\begin{array}{l}\text {-capacidade de percepção em relação a a } \\
\text { aspectos culturais } \\
\text {-capacidade de percepção em relação a } \\
\text { operações técnicas }\end{array}$ & $\begin{array}{l}\text {-seletividade } \\
\text {-disponibilidade }\end{array}$ \\
\hline
\end{tabular}

Fonte: YIN (2015, p. 113)

A análise dos dados coletados também é muito importante no estudo de caso. A análise de dados consiste em examinar, categorizar, classificar em tabelas, ou, do contrário, recombinar evidências tendo em vista proposições iniciais de um estudo de caso. Yin(2015) cita três estratégias analíticas gerais. São elas:

- Baseada em proposições teóricas: Seguir as proposições teóricas que levaram ao estudo de caso. Essas proposições refletem o conjunto de questões da pesquisa e as revisões feitas na literatura sobre o assunto e as novas interpretações que possam surgir.

- Pensando sobre explanações concorrentes: Definir e testar explanações concorrentes ; proposições originais talvez possam incluir hipóteses concorrentes.

- Desenvolvendo uma descrição de caso: é desenvolver uma estrutura descritiva a fim de organizar o estudo de caso.

Yin (2015) esclarece sobre os testes de caso para julgar a qualidade do projeto:

Validade de constructo: estabelecer medidas operacionais corretas para os conceitos que estão sob estudo.

Validade interna: (apenas para estudos explanatórios (causais), e não para estudos descritivos ou exploratórios): estabelecer uma relação causal, por meio da qual são mostradas certas condições, como diferenciada de relações falsas.

Validade externa: Estabelecer o domínio ao qual as descobertas de um estudo podem ser generalizadas. 
Confiabilidade: Demonstrar que as operações de um estudo- como os procedimentos de coleta de dados- podem ser repetidas, apresentando os mesmos resultados.

A seguir, uma síntese dos passos para a realização de pesquisas que adotam como estratégia o estudo de caso, de Freitas; Jabbour (2011):

- Definir qual é a melhor abordagem, qualitativa ou quantitativa, a fim de atender ao problema e aos objetivos da pesquisa;

- Contextualizar o objetivo da pesquisa verificando se possui fins exploratórios, se procura levantar situações ainda pouco verificadas; ou se tem fins descritivos, visando a descrever características de determinado evento, situação ou organização;

- Determinar o escopo, ou seja, se a pesquisa pretende descrever, testar ou desenvolver uma nova teoria;

- Avaliar qual é o melhor tipo de estudos de caso: único, múltiplo, incorporado ou holístico, procurando sempre definir os casos, de modo que essa definição permita generalizações;

- Elaborar as regras gerais da condução da pesquisa, em outros termos, o protocolo;

- Organizar e planejar os instrumentos de coleta de dados e evidências, procurando sempre utilizar múltiplas fontes, para permitir a validade interna da pesquisa;

- Adotar as estratégias de análise condizentes com o objetivo, problema e finalidades da pesquisa, priorizando o cruzamento das evidências com a sustentação teórica.

Assim, conforme a apresentação dos conceitos da seção 2 e da fundamen tação téorica da seção 3 deste artigo, segue a seguir os devidos procedimentos metodologicoas propostos para análise das dissertaçãoes levantadas.

\section{Procedimentos metodológicos}

Buscamos neste artigo descobrir como está sendo utilizada a metodologia de "Estudo de caso" nas dissertações na área de ciência da informação. Foi feito o levantamento apenas de dissertações, de 2017, da Ciência da Informação, para identificar quais utilizaram o estudo de caso em sua metodologia e como foram utilizados esses estudos de caso. Para a pesquisa utilizou-se a base de dados BDTD (Biblioteca Digital Brasileira de Teses e Dissertações).

A busca foi feita por trabalhos direcionados a metodologia de Estudo de Caso e Ciências da Informação. O termo utilizado para a busca foi "estudos de caso" and "ciência da informação". A princípio a base de dados retornou um resultado de 385 trabalhos, em seguido foi feito o refinamento da busca direcionado para o tipo de documento: "Dissertação", 
obtendo um resultado de 312 trabalhos, e posteriormente com um novo refinamento na busca para Ano de Defesa: "2017", obtendo um novo resultado de 26 trabalhos. Dentre os 26 artigos, após a leitura dos resumos, foram constatados que 23 eram direcionados para a metodologia do estudo de caso, e que, também eram direcionados a alguma área de pesquisa da Ciência da informação, dessa forma os três artigos excluidos não apresentavam em seu conteúdo a metodologia de estudo de caso para a analise.

Quadro 2 - Dissertações analisadas

\begin{tabular}{|c|c|c|}
\hline Autor & Titulo da Dissertação & Repositório \\
\hline $\begin{array}{l}\text { LOURENÇO, Patricia } \\
\text { Mota }\end{array}$ & $\begin{array}{l}\text { O uso do material didático impresso de educação à distância na } \\
\text { graduação presencial: estudo de caso }\end{array}$ & UFF \\
\hline $\begin{array}{ll}\text { BANDIM, Marcio } \\
\text { Aercio Silva }\end{array}$ & $\begin{array}{l}\text { Indexação automática por atribuição de artigos científicos da } \\
\text { área de ciência da informação }\end{array}$ & UFPE \\
\hline $\begin{array}{l}\text { LIMA, Rafaela Gomes } \\
\text { Gueiros Rodrigues de }\end{array}$ & $\begin{array}{l}\text { Curadoria e educação : a Ciência da Informação como } \\
\text { abordagem para construção de uma prática dialógica }\end{array}$ & UnB \\
\hline $\begin{array}{l}\text { MENDONÇA, } \\
\text { Germana Oliveira } \\
\text { Almeida de }\end{array}$ & $\begin{array}{l}\text { Acesso à informação pública na UFPB: estudo de caso da } \\
\text { Coordenação de Contabilidade e Finanças da PRA }\end{array}$ & UFPB \\
\hline $\begin{array}{l}\text { RIBEIRO, Hanna } \\
\text { Carvalho Lessa }\end{array}$ & $\begin{array}{l}\text { Participação política a partir de iniciativas online: } \\
\text { possibilidades, limites e desafios para a democracia }\end{array}$ & $\mathrm{IBICT}$ \\
\hline $\begin{array}{ll}\text { CASSOTA, } & \text { Maria } \\
\text { Luiza Jurema }\end{array}$ & $\begin{array}{l}\text { Sistema de recomendação de objetos de aprendizagem digitais } \\
\text { para e-learning: um estudo de caso em curso superior à } \\
\text { distância da UFSC }\end{array}$ & UFSC \\
\hline $\begin{array}{ll}\text { GERBASI, } & \text { Noadya } \\
\text { Tamillys } & \text { Oliveira } \\
\text { Duarte } & \\
\end{array}$ & $\begin{array}{l}\text { Compartilhamento de informações e conhecimentos na } \\
\text { comunidade virtual do SIGAA/UFPB }\end{array}$ & UFPB \\
\hline BEDIN, Jéssica & $\begin{array}{l}\text { A atuação do bibliotecário escolar na formação de estudantes } \\
\text { pesquisadores no ensino médio }\end{array}$ & UFSC \\
\hline $\begin{array}{l}\text { FREITAS, Lidiane } \\
\text { Marques }\end{array}$ & $\begin{array}{l}\text { A organização do conhecimento sensível sob a ótica da } \\
\text { arquivologia: um estudo de caso na Embrapa Soja }\end{array}$ & UEL \\
\hline $\begin{array}{ll}\text { CARNEIRO, } & \text { Adailto } \\
\text { Fernandes }\end{array}$ & Gestão do conhecimento: um estudo no âmbito do ISCP & UCB \\
\hline $\begin{array}{l}\text { NOGUEIRA, Rodrigo } \\
\underline{\text { de Freitas }}\end{array}$ & $\begin{array}{l}\text { Recuperação da informação na descrição de documentos } \\
\text { fotográficos de arquivo e a possibilidade de uso de uma } \\
\text { ontologia leve: estudo de caso DigifotoUnB }\end{array}$ & UnB \\
\hline $\begin{array}{l}\text { SILVA, Isabela Costa } \\
\underline{\mathrm{da}}\end{array}$ & $\begin{array}{l}\text { Gestão de documentos e transparência dos atos públicos: um } \\
\text { estudo de caso sobre os processos de licitação da Universidade } \\
\text { Federal Fluminense }\end{array}$ & UFF \\
\hline $\begin{array}{l}\text { FERREIRA, } \\
\text { Felipe }\end{array}$ & $\begin{array}{l}\text { Contribuição da competência em informação para a } \\
\text { aprendizagem organizacional: um estudo de caso no Centro } \\
\text { Incubador de Empresas de Marília 'Miguel Silva' }\end{array}$ & UNESP \\
\hline $\begin{array}{l}\text { CORREA, } \\
\text { Figueiredo }\end{array}$ & $\begin{array}{l}\text { Gestão da memória organizacional com transferência do } \\
\text { conhecimento e melhoria de um processo crítico: o caso de uma } \\
\text { agência reguladora brasileira }\end{array}$ & UCB \\
\hline SANTOS, Eunice de & As políticas de informação digital adotadas nas escolas públicas & UFBA \\
\hline
\end{tabular}




\begin{tabular}{|c|c|c|}
\hline Jesus & no Nordeste & \\
\hline $\begin{array}{l}\text { CARVALHO, Priscila } \\
\text { Freitas de }\end{array}$ & $\begin{array}{l}\text { Os efeitos da lei de acesso à informação na gestão das } \\
\text { informações arquivísticas: caso da Universidade Federal do } \\
\text { Estado do Rio de Janeiro }\end{array}$ & UFF \\
\hline FUZARO,Paula Padial & $\begin{array}{l}\text { A gestão do conhecimento e a atuação do secretário executivo } \\
\text { na UEL }\end{array}$ & UEL \\
\hline $\begin{array}{l}\text { SARAIVA, Natália de } \\
\underline{\text { Lima }}\end{array}$ & $\begin{array}{l}\text { IMAGINE : análise do ciclo da informação na representação de } \\
\text { fotos-conceito }\end{array}$ & UnB \\
\hline $\begin{array}{l}\text { RAMÍREZ,Diana } \\
\text { Marcela Bernal }\end{array}$ & $\begin{array}{l}\text { Gestão do conhecimento : análise das competências } \\
\text { necessárias para sua aplicação no Arquivo da Justiça do } \\
\text { Trabalho de Londrina }\end{array}$ & UEL \\
\hline $\begin{array}{l}\text { PINTO, Mariana de } \\
\underline{\text { Azevedo }}\end{array}$ & $\begin{array}{l}\text { Entropia informacional e desinformação - um estudo acerca da } \\
\text { organização da informação aplicada no sistema de informação } \\
\text { governamental do Programa Mais Médicos }\end{array}$ & UFBA \\
\hline $\begin{array}{ll}\text { SILVA, } & \text { Rachel } \\
\text { Polycarpo da } & \end{array}$ & $\begin{array}{l}\text { Biblioteca para quem não sabe ler?: a quebra de paradigma } \\
\text { sobre leitura, leitores, usuários de bibliotecas e o papel do } \\
\text { bibliotecário escolar na educação infantil }\end{array}$ & UFF \\
\hline $\begin{array}{l}\text { CARVALHO, Dainane } \\
\text { Silva }\end{array}$ & $\begin{array}{l}\text { O caráter da produção, organização e uso da informação em } \\
\text { museus: o caso do Museu da Abolição em Recife - PE }\end{array}$ & UFPE \\
\hline $\begin{array}{ll}\text { SILVA, } & \text { Rafaela } \\
\text { Carolina da } & \end{array}$ & $\begin{array}{l}\text { Gestão em bibliotecas públicas no contexto híbrido: um estudo } \\
\text { comparativo de bibliotecas híbridas no âmbito nacional e } \\
\text { internacional em prol do desenvolvimento de comunidades }\end{array}$ & UNESP \\
\hline
\end{tabular}

Fonte: BDTD, 2018.

Após desta breve triagem, delimitamos alguns parâmetros para análise pré-definidos das dissertações, de acordo com a revisão realizada anteriormente, e destacamos as categorias que foram criadas e baseadas em Yin (2015). Assim, a análise das dissertações segue as seguintes categorias propostas:

- Tipo de abordagem: qualitativa, quantitativa ou quali-quanti;

- Tipo de estudo de caso: Único, Múltiplos, com enfoque incorporado ou enfoque holístico;

- Propósito: Descritivo, Exploratório, Explanatório;

- Coleta de evidências utilizada: Documentação, registros em arquivos, entrevistas, observações diretas, observação participante, artefatos físicos;

- Estratégia adotada para análise dos dados: proposições teóricas, explanações concorrentes, desenvolvimento de uma descrição de caso.;

- Estruturas para estudos de caso: Analítica linear, Comparativa, Cronológica, De construção de teoria, De "suspense", Não-sequencial.

Os 23 artigos restantes foram analisados conforme as categorias propostas por Yin (2015), e em alguns casos a percepção dos pesquisadores foram necessárias para realzar a análisedas categorias pois a mesma não estavam tão claras assim nos textos. Criamos uma 
planilha na ferramenta Microsoft Excel para tabulação dos dados, de acordo com as categorias propostas por Yin (2015), e com uma leitura mais precisa das dissertações, direcionadas ao resumo, ao sumário, ao capítulo de metodologia e de coleta e análise de dados pudemos recolher os dados pertinentes das dissertações de acordo com as categorias propostas.

\section{Resultados e discussão}

Esse subtópico do artigo tem por finalidade relatar de forma sistematizada os resultados encontrados no estudo por meio de elementos gráficos e apresentar a discussão dos resultados da visualização dos dados encontrados nos gráficos. Esta discussão é guiada conforme a proposta de utilização de categorias abordados por Yin (2015), como parâmetros, pré-definidos na análise, e com o objetivo de responder as questões e objetivos desta pesquisa.

Gráfico 1: Abordagem da pesquisa

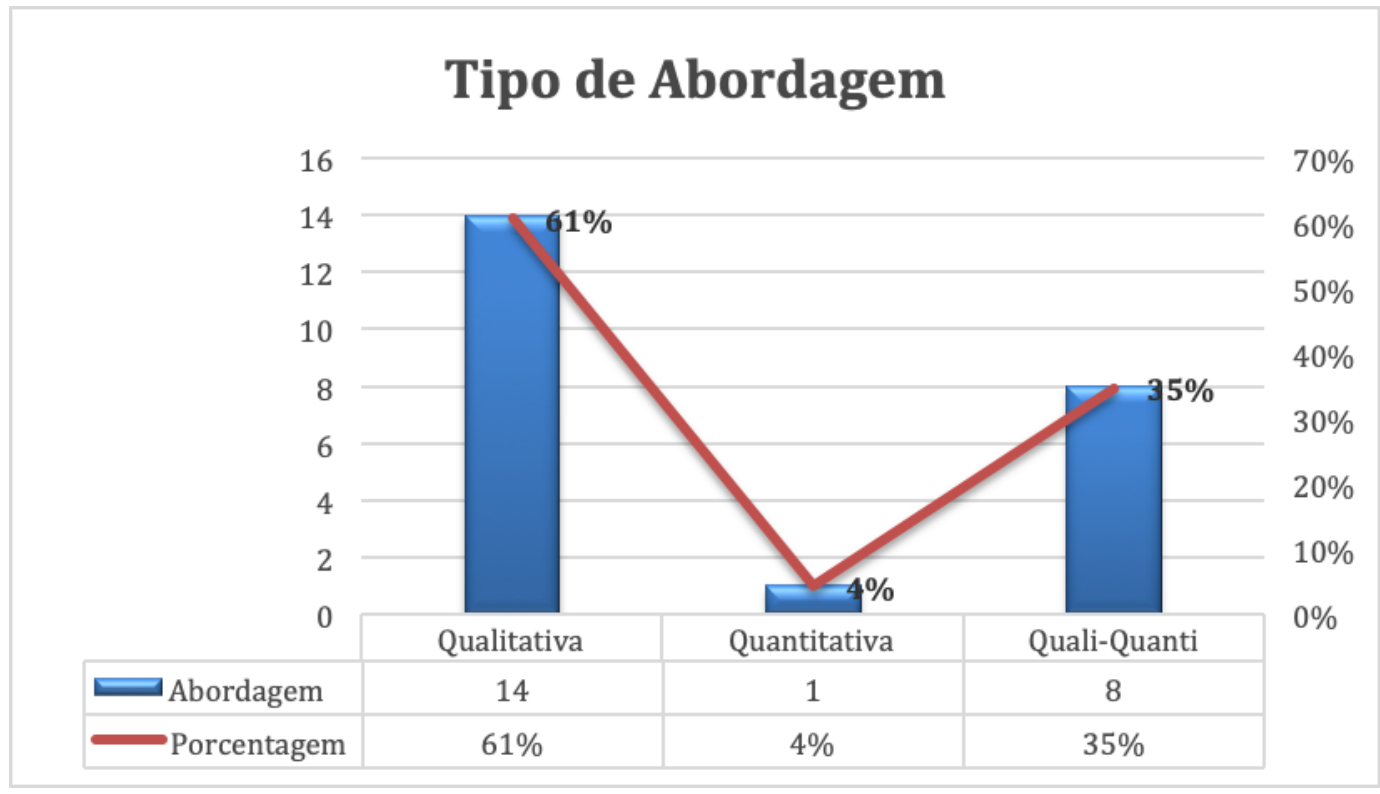

FONTE: Elaborado pelos autores.

De acordo com o gráfico 1, identificamos que das 23 dissertações analisadas, 61\% ( 14 dissertações) apresentaram a abordagem de pesquisa qualitativa, 4\% (ou seja, apenas 1 dissertação) apresentou a abordagem quantitativa, e 35\% (8 dissertações) apresentaram a abordagem quali-quanti, ou seja, tanto a abordagem qualitativa como a abordagem quantitativa. Podemos perceber desta forma, que abordagem de pesquisa qualitativa em metodologia de estudo de caso é predominante na escolha da produção destas dissertações. 
Gráfico 2: Tipologia de estudo de caso

\section{Tipo de estudo de caso}

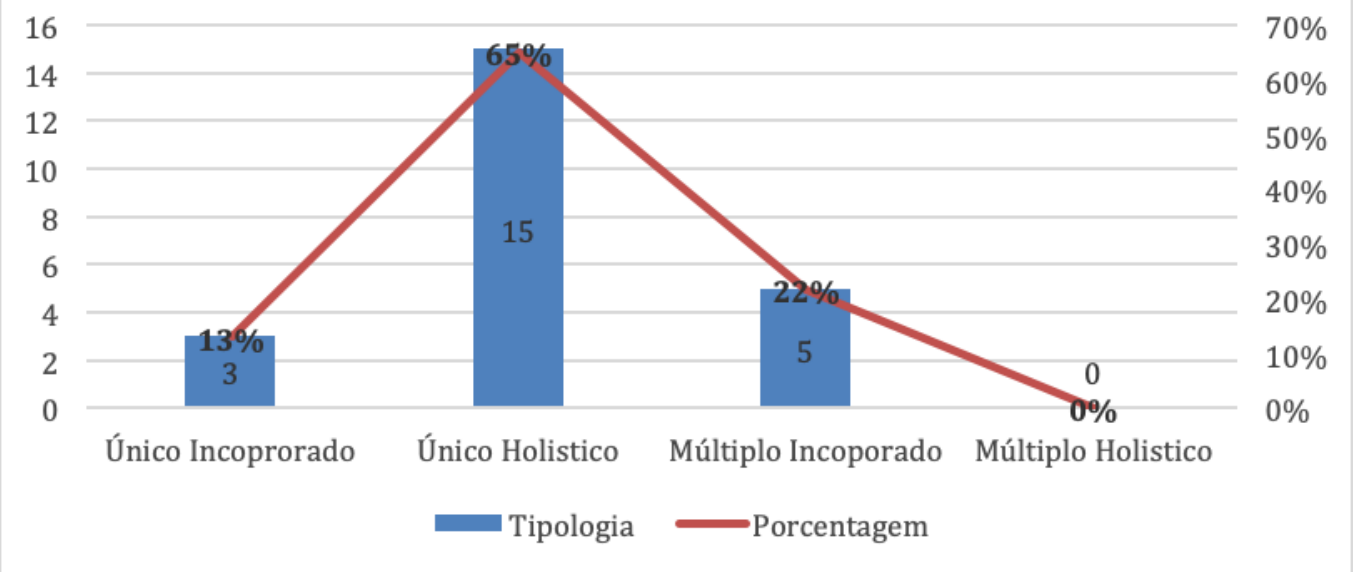

Fonte: Elaborado pelos autores.

A análise do gráfico 2 indica que, quanto às tipologias utilizadas nos estudos de casos, das 23 dissertações analisadas, 65\% (15 dissertações) utilizam o estudo de caso único holístico, 22\% (5 dissertações) utilizam o estudo de caso múltiplo incorporado, 13 \% (3 dissertações) utilizam o estudo de caso único incorporado, sendo, que, não houve constatação da utilização dos estudos de casos múltiplos holísticos nas dissertações analisadas. Assim, percebe-se que o estudo de caso único holístico, voltado para a análise de uma unidade, é o mais utilizado nas dissertações.

Gráfico 3: Proposta da pesquisa

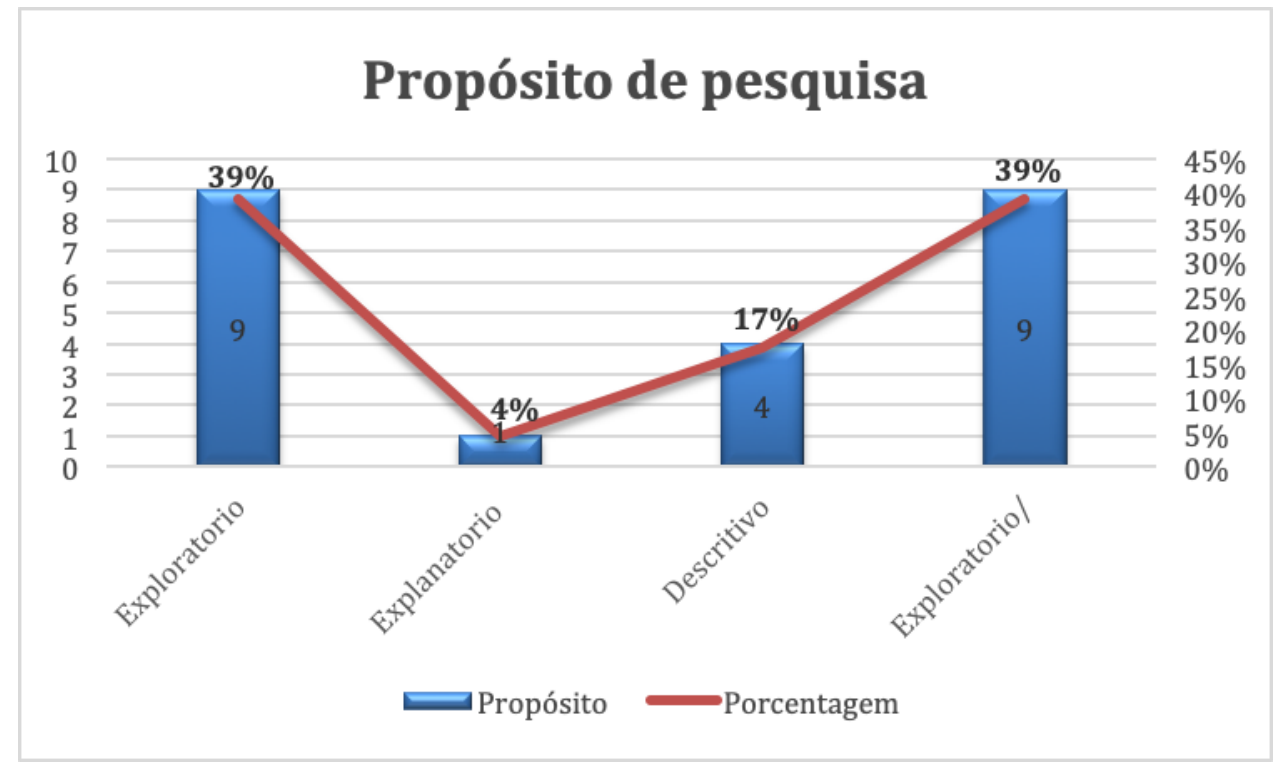

Fonte: Elaborado pelos autores.

O gráfico 3 apresenta a análise das dissertações quanto ao seu objetivo ou proposta de pesquisa. Aqui configura-se a porcentagem de $100 \%$ ( 23 dissertações), para cada tipo de 
objetivo ou proposta. Percebemos que 39\% (9 dissertações) utilizam somente o objetivo exploratório, 17\% (4 dissertações) utilizam somente o objetivo descritivo, e 4\% (apenas 1 dissertação) utiliza o objetivo de proposta explanatório, 39\% (9 dissertações) utilizam conjuntamente os tipos de objetivo Exploratório/Descritivo, conforme análise das dissertações.

Os estudos exploratórios são, talvez, segundo Yin (2015), os de reputação mais notória. Por outro lado, os estudos descritivos representam a descrição completa de um fenômeno inserido no seu contexto. Os estudos explanatórios procuram informação que possibilite o estabelecimento de relações de causa-efeito, ou seja, procuram a causa que melhor explica o fenômeno estudado e todas as suas relações causais.

Gráfico 4: Fontes de evidência

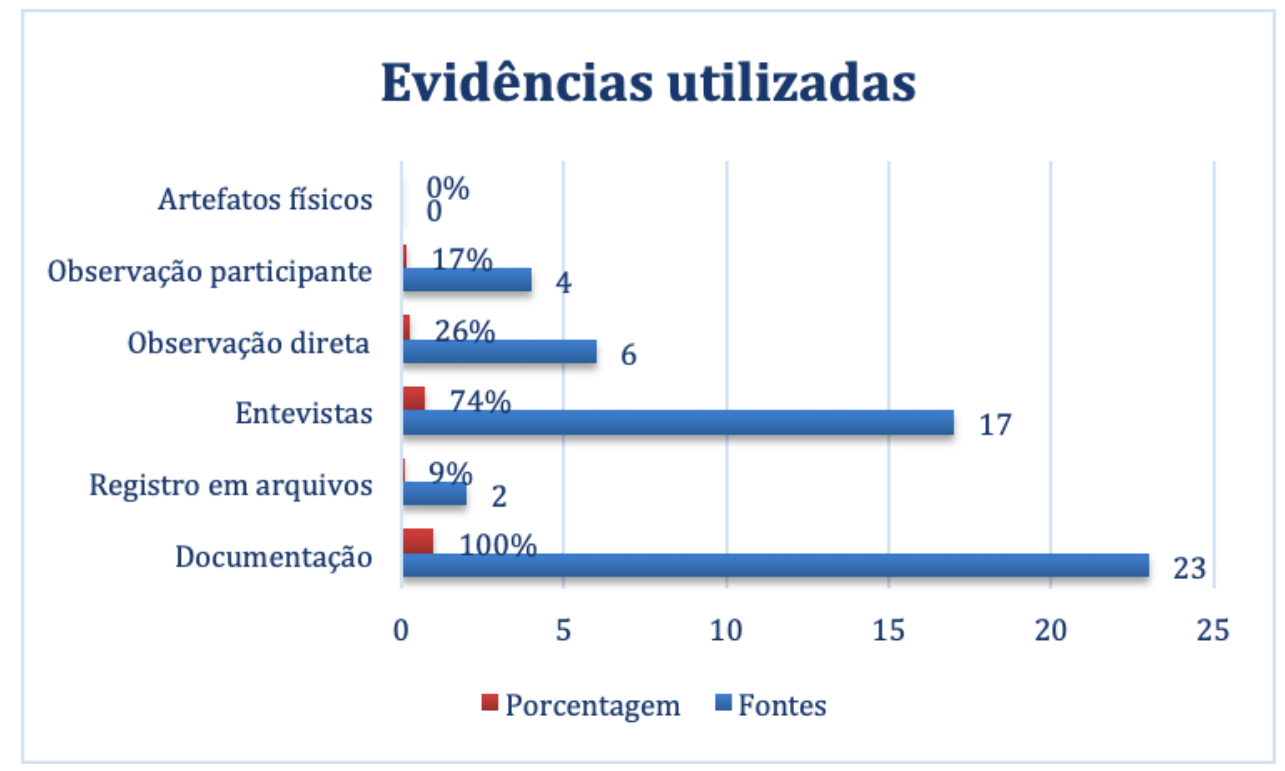

Fonte: Elaborado pelos autores.

Segundo o gráfico 4, de Fontes de evidência, notamos que, 100\%, ou seja, todas as 23 dissertações analisadas recorrem a documentação como evidência para seus estudos de caso, 74\% (17 dissertações) recorrem a algum tipo de entrevistas como evidência para seus estudos de caso, 26\% (6 dissertações) recorrem a observação direta como evidência para seus estudos de caso, 17\% (4 dissertações) recorrem a observação participante como evidência para seus estudos de caso, 9\% (2 dissertações) recorrem registros em arquivos como fonte de evidência para seus estudos de caso. Não houve registro de utilização de artefatos físicos nas dissertações analisadas.

Percebemos que as evidências para o estudo de caso derivam de várias fontes, e cada uma tem suas características que as distinguem para tal coleta de dados ou evidências. Como analisado, a documentação, é utilizada em todas as dissertações, sendo um tipo de fonte de evidência imprescindível para todos os tópicos de estudo de caso.

Gráfico 5: Quantidade de Fontes Utilizadas 


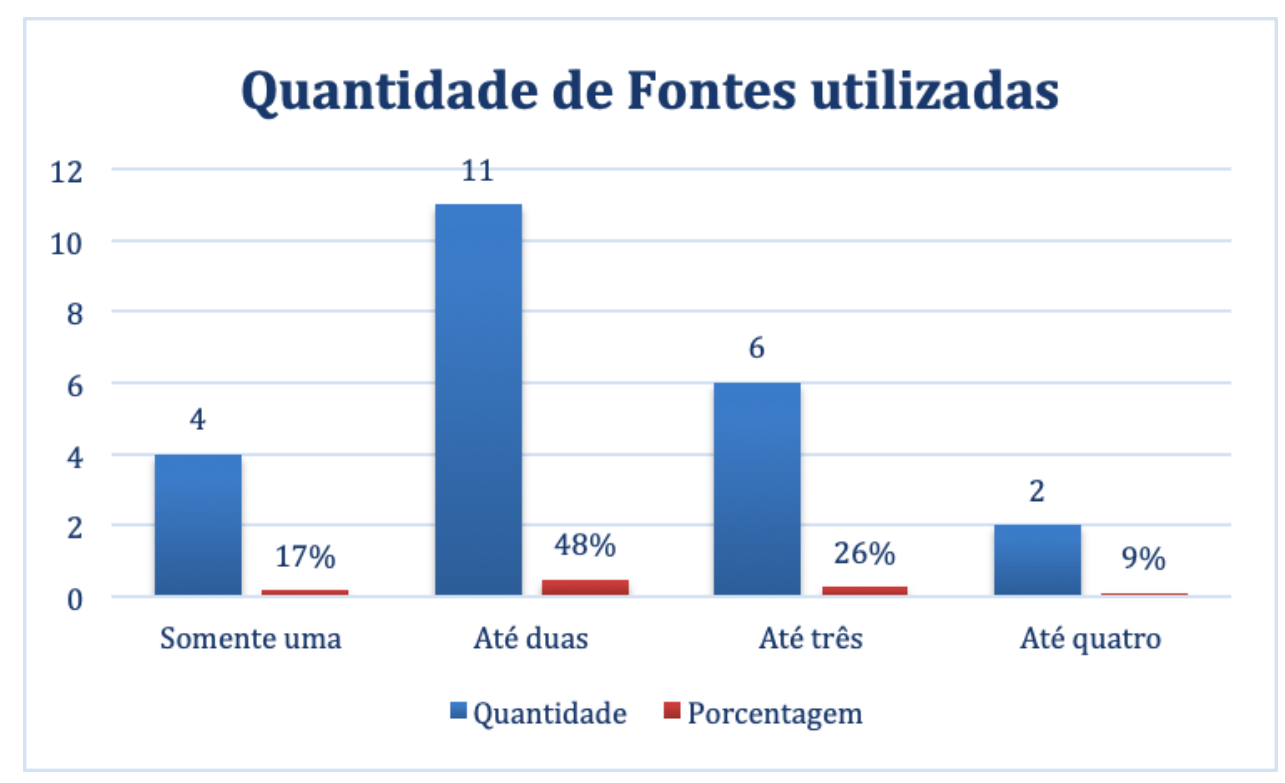

Fonte: Elaborado pelos autores.

Fazendo a correspondência do gráfico 5 com o gráfico 4, podemos perceber que $17 \%$ (4 dissertações) utilizam apenas um fonte de evidência para seu estudo de caso, ou seja, utilizam somente a documentação como fonte de evidência, 52\% (12 dissertações) utilizam até duas fontes de evidência, ou seja, a documentação simultaneamente com as entrevistas, $26 \%$ (6 dissertações) utilizam até três fontes de evidência, ou seja, a documentação, as entrevistas, alternando com a observação direta e a observação participativa, 9\% (2 dissertações) utilizam até quatro fontes de evidência, ou seja, a documentação, as entrevistas, os registros de arquivos e a participação direta.

Nesta análise é percebida a utilização das várias fontes de evidência para a coleta de dados em um estudo de caso. De acordo com Yin (2015), abordagem às fontes individuais de evidência, não é recomendado quando se conduzem pesquisas de estudos de caso, a riqueza do uso de múltiplas fontes de dados fornecem várias avaliações do mesmo fenômeno. 
Gráfico 6: Análise de evidências

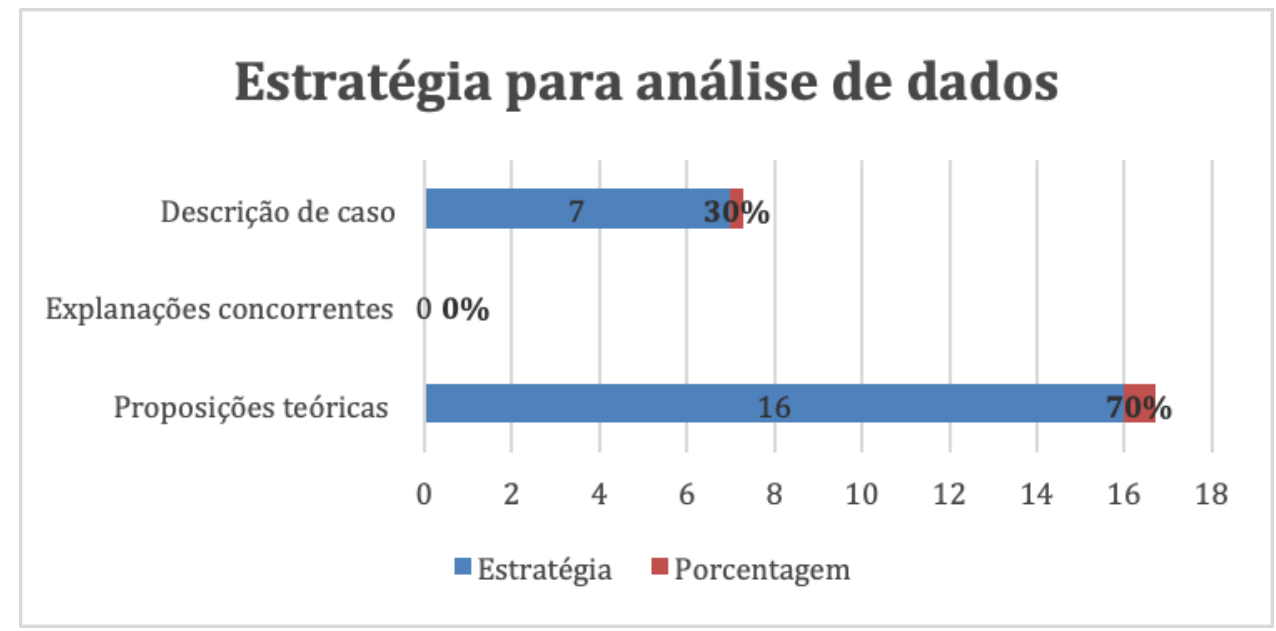

Fonte: Elaborado pelos autores.

De acordo com o gráfico 5, percebemos que a maioria das dissertações, 70\% (16 dissertações) utilizam como estratégia para análise de suas evidências as proposições teóricas, 30\% (7 dissertações) utilizam descrições de caso como estratégia para análise de suas evidências, sendo que não houve registro do uso das explanações concorrentes como estratégia para análise de suas evidências.

Yin (2015), relata o desafio nesta parte de estratégia de análise das evidências do estudo de caso, pois é uma parte menos desenvolvida nos estudos e os pesquisadores começam os estudos de caso sem a menor noção de como a evidência deverá ser analisada.

Gráfico 7:: Composição dos estudos de caso

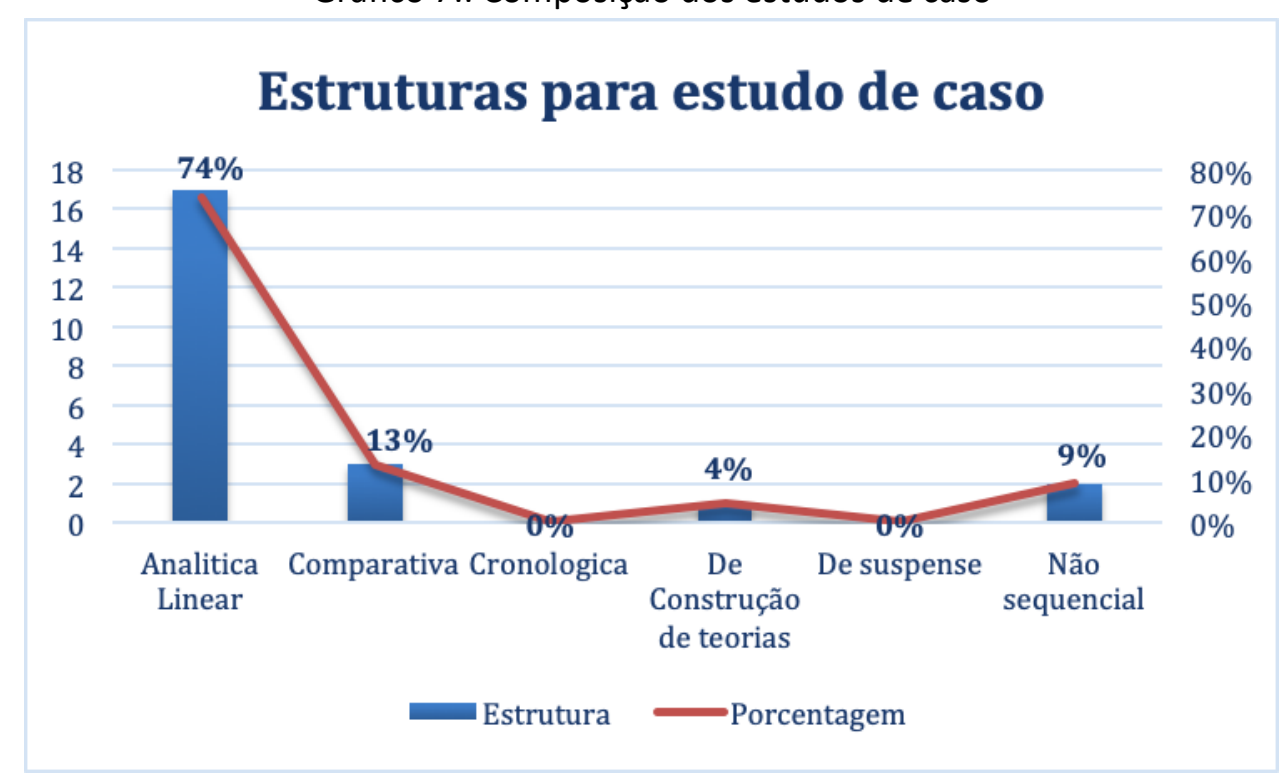

Fonte: Elaborado pelos autores. 
$\mathrm{Na}$ análise do gráfico 6, identificamos que a maioria das 23 dissertações analisadas 74\% (17 dissertações) organizam sua estrutura composicional dos estudos de caso, utilizando o tipo analitica linear, 13\% (3 dissertações) organizam sua estrutura composicional dos estudos de caso, utilizando o tipo comparativo, 9\% (2 dissertações) organizam sua estrutura composicional dos estudos de caso utilizando o tipo não sequencial, 4\% ( apenas uma dissertação) organizam sua estrutura composicional dos estudos de caso utilizando o tipo de construção de teorias, sendo que não houve registro do uso de estruturas composicionais para os tipos de cronologia e de suspense.

\section{Discussão}

O estudo de caso é um método utilizado desde a antiguidade clássica, mas com esforços de protocolo para um prática unificada somente no século XX. O estudo de caso é uma estratégia que requer a compreensão empírica do fenômeno pesquisado, utilizando-se de abordagens quantitativas e/ou qualitativas para atender o problema e objetivos da pesquisa;

O método de estudo de caso, em geral, é constituído de uma multiplicidade de abordagens, é um terreno controverso, e marcado pela variedade de perspectivas. Apesar dos parâmetros criados por Yin para pensar e discutir o método, ainda não há consenso sobre sua concepção e realização dificultando sua aplicação e evolução.

Atentar para as limitações e dificuldades que implicam a necessidade de um projeto viável para os pesquisadores, que permita levantar uma pesquisa de Estudo de Caso com uma preparação prévia e uma estrutura adequada.

Durante a realização da análise das dissertações, percebemos que há várias maneiras de uso do método. Os pesquisadores citam diversos autores, o que é normal visto a quantidade de literatura encontrada sobre o estudo de caso. Os autores destacam em suas dissertações que utilizaram o método estudo de caso mas não especificam claramente como este foi conduzido de forma mais detalhada. $\mathrm{O}$ que pode ser compreendido como falta de pesquisa sobre $\mathrm{o}$ método estudo de caso, que como conseqüência, na hora de elucidar isso na metodologia da pesquisa, não fica bem claro quais foram os procedimentos adotados para executá-lo. Sendo assim, foi necessário uma análise mais profunda da dissertação para conseguirmos compreender em quais parâmetros deveríamos encaixá-la dentro do estudo. Sugere-se então uma busca aprimorada na bibliografia sobre estudo de caso, no momento de contrução da metodologia das dissertaçãoes, para um melhor detalhamento da construção do metodo.

Outro aspecto a ser observado é que o estudo de caso é muito utilizado no ano de 2017 em dissertações no campo da Ciência da Informação como analisado, se pensarmos no número total de dissertações recuperadas e quantas utilizaram o método ( $88 \%$ do total). Isso 
se justifica pelo fato de que o estudo de caso traz estratégias para compreender os fenômenos sociais complexos e contemporâneos abordados pelo campo da Ciência da Informação, e dessa forma ampara e amplia a pesquisa na Ciência da Informação praticada no país.

\section{Referências}

ANDRÉ, Marli Eliza Dalmazo Afonso. Estudo de caso em pesquisa e avaliação educacional. Brasília: Líber Livro Editora, 2005.

FREITAS, Wesley R. S.; JABBOUR, Charbel J. Utilizando estudo de caso(s) como estratégia de pesquisa qualitativa: boas práticas e sugestões. Estudo \& Debate, Lajeado, v. 18, n. 2, p. 07-22, 2011. Disponível em:https://repositorio.unesp.br/handle/11449/134684 Acesso em: 12 set. 2018.

GIL, A. C. Como elaborar projetos de pesquisa. 4. ed. São Paulo: Atlas, 2007.

INSTITUTO BRASILEIRO DE INFORMAÇÃO EM CIÊNCIA E TECNOLOGIA (IBICT). BDTD: Biblioteca Digital Brasileira de Teses e Dissertaçãoes, 2002. Página Incial. Disponível em: http://bdtd.ibict.br/vufind/ Acesso em:12 set. 2018.

MARTINS, Gilberto Andrade. Estudo de caso: uma reflexão sobre aplicabilidade no Brasil. Revista de Contabilidade e Organizações, São Paulo, v. 2, n. 2, p. 8, 18 jan./abr. 2008. Disponível em: http://www.revistas.usp.br/rco/article/view/34702/37440 Acesso em: 12 set. 2018.

MEIRINHOS, Manuel; OSÓRIO, Antônio. O estudo de caso como estratégia de investigação em educação. EDUSER: revista de educação, v. 2, n. 2, 2010. Disponível em: https://www.eduser.ipb.pt/index.php/eduser Acesso: 11 set. 2018.

MERRIAM, S. B. Qualitative research and case study applications in education. San Francisco: Jossey-Bass, 1998.

STAKE, Robert E. The art of case study research. Thousand Oaks: SAGE, 1995.

YAZAN, Bedrettin. Três abordagens do método de estudo de caso em educação. Meta: Avaliação, Rio de Janeiro, v. 8, n. 22, p. 149-182, jan. /abr. 2016. Disponivel em: http://revistas.cesgranrio.org.br/index.php/metaavaliacao/article/view/1038/pdf1 Acesso: 11 set. 2018.

YIN, Robert K. Estudo de caso: planejamento e métodos. Porto Alegre: Bookman, 2005.

YIN, Robert K. Estudo de caso: planejamento e métodos. 5. ed. Porto Alegre: Bookman, 2015. 